\title{
Unbalance Glycometabolic in Elderly Woman None Diabetic COPD Patients
}

\author{
Tiziana Ciarambino ${ }^{\mathrm{a}, \mathrm{e}}$, Mauro Giordano ${ }^{\mathrm{b}}$, Giovanna Menco $^{\mathrm{a}}$, Bruno Moncharmont ${ }^{\mathrm{c}}$, \\ Nicola Ferrara ${ }^{\mathrm{d}}$, Giuseppe Paolisso ${ }^{\mathrm{b}}$, Cecilia Politi $^{\mathrm{a}}$
}

\begin{abstract}
Background: It has been estimated that by 2020, the Chronic Obstructive Pulmonary Disease (COPD) will be the third place among the most important causes of death in all over the world. Studies focusing on risk factors that influence the admission or readmission to the hospital are limited. The administration of medications can contribute to unplanned readmission. Moreover, in the course of COPD, treatment with cortisone determines a high risk of worsening of glucose control. The guidelines on the management of COPD do not address this issue in detail, although the number of COPD patients with diabetes mellitus is considerable and significant. Clinical studies designed specifically on this population are needed in order to identify effective and safe therapeutic pathways.
\end{abstract}

Methods: We conducted an observational, descriptive study in a health area of the Molise Region that included 300 elderly subjects aged $\geq 65$ and followed from June 2012 to June 2013 .

Results and Conclusions: Our preliminary study revealed that the prevalence of unbalance glycometabolic (as indicated by $\mathrm{HbAlc}$ $>7 \%$ ) in COPD patients was $>50 \%$. In particular, this difference was more frequent in COPD woman patients and it warrants further investigation.

Keywords: Elderly; COPD; Glicometabolic unbalance; Gender

Manuscript accepted for publication October 9, 2013

${ }^{a}$ Dept Internal Medicine, Hospital F. Veneziale Isernia, Italy

${ }^{\mathrm{b}}$ Dept Gerontology, Geriatrics and Metabolic Diseases, Second

University of Naples, Italy

${ }^{c}$ Faculty of Medicine University of Molise, Italy

${ }^{\mathrm{d} D e p t}$ Internal Medicine, University of Federico II Naples, Italy

${ }^{\mathrm{e}}$ Corresponding author: Tiziana Ciarambino, Dept Internal Medicine,

Hospital F. Veneziale Isernia, Italy.

Email: tiziana.ciarambino@virgilio.it

doi: http://dx.doi.org/10.4021/jem194e

\section{Introduction}

The Chronic Obstructive Pulmonary Disease (COPD) is described as a group of lung diseases characterized by airflow limitation and by chronic inflammation of the bronchioles [1]. COPD is a major cause of morbidity and mortality in the world and remains a serious public health problem. Acute exacerbations of COPD are a common cause of hospitalization and readmission rates [2]. An exacerbation of COPD is an acute event characterized by a worsening of the patient's respiratory symptoms that is beyond normal day to day variations and leads to a change in medication [3].

In hospital, mortality of patients admitted for a hypercapnic exacerbation with acidosis is approximately $10 \%$ [4]. Mortality reaches $40 \%$ at 1 year after discharge in those needing mechanical support, and all cause mortality, 3 years after hospitalization, is as high as $49 \%$ [5]. Prevention, early detection and prompt treatment of exacerbations are vital to reduce the burden of COPD [6]. The cause of about one-third of severe exacerbations of COPD cannot be identified [1].

Clinical factors, such as poor self-management and problems with the administration of medications can contribute to unplanned readmission [1]. In this regard, treatment with glucocorticoids during exacerbations of COPD determines a high risk of worsening of glucose control [7]. The guidelines on the management of COPD do not address this issue in detail, although the number of COPD patients with diabetes mellitus is considerable and significant [1]. Several controlled clinical trials have demonstrated the efficacy in terms of clinical and functional treatment with cortisone which must however be short and not too high dosages.

Few studies have demonstrated the difference in unbalance glucometabolic between gender. Our preliminary study revealed that the prevalence of unbalance glycometabolic (as indicated by $\mathrm{HbAlc}>7 \%$ ) in COPD patients was $>50 \%$. In particular, this difference was more frequent in elderly COPD woman patients.

\section{Materials and Methods}

We conducted an observational, descriptive study in a health 
Table 1. Clinical Characteristically at Baseline

\begin{tabular}{|c|c|c|c|c|c|}
\hline & COPD & DM2 & COPD+DM2 & CONTROLS & Pvalue \\
\hline Number (m) & $75(35)$ & $75(40)$ & $75(45)$ & $75(40)$ & ns \\
\hline Age (yr) & $76.2 \pm 1$ & $74.3 \pm 2$ & $74.7 \pm 2$ & $75.6 \pm 3$ & ns \\
\hline BMI $\left(\mathrm{kg} / \mathrm{m}^{2}\right)$ & $25.5 \pm 3$ & $26.1 \pm 2$ & $26.3 \pm 1$ & $25.4 \pm 2$ & ns \\
\hline HbA1c $(\%)$ & $8.1 \pm 0.6^{*}$ & $8.2 \pm 1.1^{*}$ & $8.0 \pm 1.0^{*}$ & $4.1 \pm 0.4$ & $<0.005$ \\
\hline Smoking (n) & 65 & 50 & 45 & 55 & ns \\
\hline Wood Smoke (n) & 10 & 25 & 30 & 20 & ns \\
\hline Glucose pre-prandial (mg/dL) & $145 \pm 7 *$ & $150 \pm 5^{*}$ & $156 \pm 3 *$ & $106 \pm 2 *$ & $<0.0001$ \\
\hline Corticosteroids therapy (n.) & 75 & - & 75 & - & ns \\
\hline Hypoglicaemic therapy (n.) & - & 75 & 75 & - & ns \\
\hline Dietotherapy (n.) & 75 & 75 & 75 & 75 & ns \\
\hline Physical exercise (n.) & 75 & 75 & 75 & 75 & ns \\
\hline FEV1 (\%) & $55^{*}$ & 85 & $50 *$ & 90 & $<0.0001$ \\
\hline
\end{tabular}

BMI: body mass index; COPD: chronic obstructive pulmonary disease; DM2: type 2 diabetes. Values are expressed by mean \pm SE.

area of the Molise Region (Isernia Hospital F. Veneziale, Dept Internal Medicine) that included 300 elderly subjects aged $\geq 65$ and followed from June 2012 to June 2013 .

The inclusion criteria were: older than 65 years; COPD diagnosis based on symptoms, FEV $1<60 \%$ of the predicted value, history of significant exposure to tobacco smoke $(>20$ packs/year) or wood smoke ( $>20$ years) and optimal medical therapy according to guidelines GOLD $[1,8]$.

The exclusion criteria were: history of exposure to both risk factors (tobacco and wood smoke); less than one year of exposure cessation; contraindications for methacholine challenge test (MCT); respiratory disease other than COPD, especially asthma (medical diagnosis or high probability: recurrent episodes of wheezing starting before 40 years old), bronchiectasis and tuberculosis.

All patients were divided into four groups: 75 patients with COPD (COPD); 75 patients with type 2 diabetes mellitus (DM2); 75 patients with both COPD and diabetes (DM2+COPD) and 75 patients who did not have COPD and diabetes (Control). COPD cases were diagnosed based on the two criteria: 1) cough with expectoration on most days of the week for 3 months of the year for at least 2 consecutive years; and 2) forced expiratory volume in 1 second (FEV1) and (FEV1)/FVC value lower than $60 \%$ predicted as diagnosed by spirometry. All the two criteria were considered as essential for diagnosis of COPD.

Spirometry was performed according to the ATS/ETS recommendations [9]. Forced expiratory volume in 1 second (FEV1) and forced vital capacity (FVC) were measured. Between three to four manoeuvres were performed under direction of trained personnel, and the values where the maximal FEV1 was reached were used. All measuring instruments were calibrated prior to each testing. The technical personnel were trained and all results were reviewed by a pulmonary physician. COPD was defined using the ratio FEV1/FVC, which is considered a sensitive measure of COPD on its own $[10,11]$. In particular, we defined two forms of COPD: GOLD 2 (moderate) was defined as $<50 \%$ FEV $1<80 \%$ predicted and the GOLD 3 (severe) as $<30 \%$ FEV $1<50 \%$ of predicted value. Both constitute the main criterion for COPD according to the Global Initiative for Chronic Obstructive Lung Disease (GOLD) criteria [1].

The outcome in this analysis was newly diagnosed type 2 diabetes from June 2012 to June 2013. We mailed a supplementary questionnaire regarding symptoms, diagnostic tests, and hyperglycemic treatments to all subjects enrolled in this study. The diagnosis of new diabetes was established when at least on of the following criteria was reported on the supplementary questionnaire: 1) one or more classic symptom (excessive thirst, polyuria, weight loss, hunger, or coma) plus a fasting plasma glucose concentration of 140 $\mathrm{mg} / \mathrm{dL}(7.8 \mathrm{mmol} / \mathrm{L})$ or a random plasma glucose concentration of $200 \mathrm{mg} / \mathrm{dL}(11.1 \mathrm{mmol} / \mathrm{L}) ; 2$ ) at least two elevated plasma glucose concentrations on different occasions (fast- 


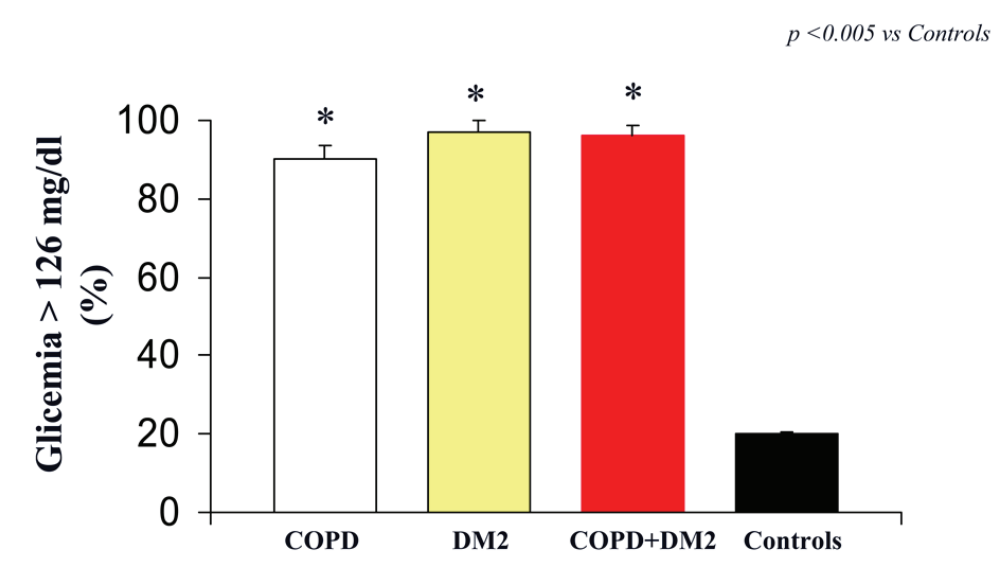

Figure 1. Glicemia (indicated as $\%$ of patients with value $>126 \mathrm{mg} / \mathrm{dL}$ ) in COPD (white column), DM2 (yellow column), COPD+DM2 (red column), and control (black column). Values are mean \pm SEM. * $\mathrm{P}<0.005$ vs $\mathrm{C}$.

ing, $140 \mathrm{mg} / \mathrm{dL}$ or $7.8 \mathrm{mmol} / \mathrm{L})$; or random, $200 \mathrm{mg} / \mathrm{dL}(11.1$ $\mathrm{mmol} / \mathrm{L}$ ) after at least $2 \mathrm{~h}$ of oral glucose tolerance testing in the absence of symptoms, or 3) treatment with hypoglycemic medication (insulin or oral hypoglycemic agents). However, we used the criteria proposed by the ADA 2013 [12].

For these four different groups of patients we extrapolated from their medical records sex, age, weight and height (from which we obtained the body mass index: BMI), whether they were smokers or non-smokers, hemoglobin $(\mathrm{Hb})$, glycosylated hemoglobin $(\mathrm{HbA} 1 \mathrm{c})$, creatinine, blood urea nitrogen (BUN), blood sugar, saturation $\left(\mathrm{SO}_{2}\right)$, c-reactive protein (CRP), FEV1, caloric intake, physical exercise and finally if they did or not use of corticosteroids or drugs hypoglycemic agents (Table 1).

All patients during the period of study, were instructed to consume a weight-maintaining diet providing about 22 $24 \mathrm{Cal} / \mathrm{kg}$ per day, $0.8-1.0 \mathrm{~g} / \mathrm{kg} /$ day per day of protein, with dietary carbohydrates and lipids represented 40 and $25 \%$ of the total caloric intake. All patients were instructed to follow a physical exercise as indicated by guidelines ESC/EASD 2007.

All COPD patients, during the period of study, were instructed to consume systemic corticosteroids (prednisone 40 $\mathrm{mg}$ /day) as indicated by guidelines GOLD [1].

The Institutional Ethics Committee approved the study and all patients signed an informed consent.

\section{Statistical analysis}

Values are expressed as mean $\pm \mathrm{SE}$. It was used the t-student to assess the differences between the different groups of patients ( $\mathrm{P}<0.005, \mathrm{P}<0.0001$ vs controls). The multivariate model adjusted age, time periods, BMI, family history of diabetes, weekly frequency of moderate-to-vigorous exercise $(<0.5,0.5-3.9,4.0-6.9$, or $7.0 \mathrm{~h})$, smoking status (never smoked, former smoker, current smoker (25 cigarettes/day), daily alcohol intake, and a dietary score variable. The dietary score variable included information on dietary predictors of type diabetes [13], including cereal fiber, transfat, glycemic load, and the ratio of polyunsaturated to saturated fat. These data were derived from a 120-item, semiquantitative, food frequency questionnaire. Each subject was assigned a score of each nutrient on the basis of quintiles of intake (a higher score represented a lower risk), and then the four scores were summed and the total score categorized into quintiles.

\section{Results}

Table 1 shows the general characteristics of our cohort of 300 patients. The mean age of the participants was 75.2 years. The median BMI of our participants was $25.8 \mathrm{~kg} / \mathrm{m}^{2}$. Approximately $13 \%$ of the participants had a family history of diabetes.

BMI, Age, smoking or wood smoke, dietotherapy and physical exercise, corticosteroids therapy, and hypoglicaemic therapy did not change between groups (Table 1).

\section{Unbalance glucometabolic}

During 1 year of follow-up, we documented 225 new cases of unbalance glycometabolic in the COPD cohort, with 150 cases of incident type 2 diabetes among the participants who had COPD. We calculated the age, BMI, and potential confounding factors for type 2 diabetes for participants with COPD compared with participants who did not have COPD.

In particular, we reported, a significantly difference in plasma glucose between COPD, DM2, COPD+DM2 and control subjects $(160 \pm 4$ vs $163 \pm 3 ; 165 \pm 1$ vs $106 \pm 2$ $\mathrm{mg} / \mathrm{dL}$; respectively, $(\mathrm{P}<0.0001$ vs control; $\mathrm{P}$ : ns COPD vs 
$p<0.0001$ vs Controls

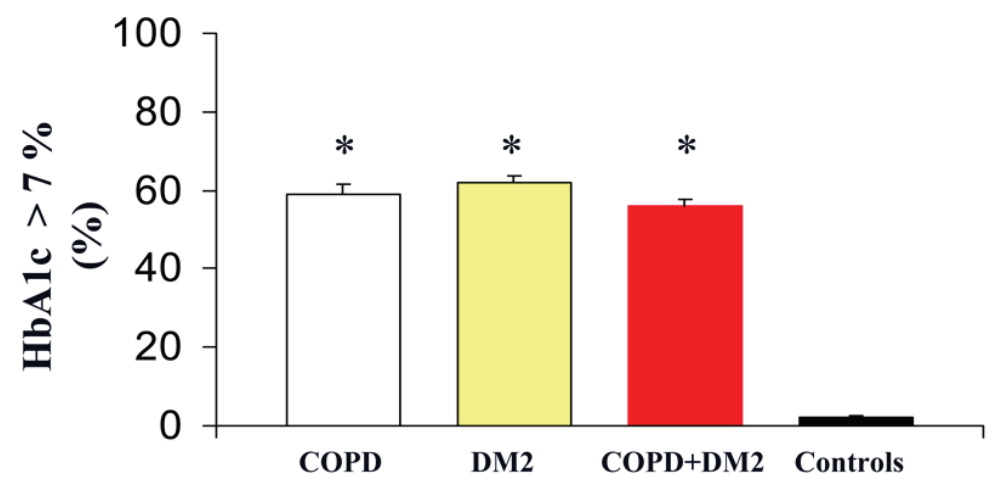

Figure 2. $\mathrm{HbA} 1 \mathrm{c}$ (indicated as $\%$ of patients with value > 7\%) in COPD (white column), DM2 (yellow column), COPD+DM2 (red column), and control (black column). Values are mean \pm SEM. ${ }^{*} \mathrm{P}<0.0001$ vs $\mathrm{C}$.

\section{DM2 vs COPD+DM2) (Fig. 1).}

However, we reported a significantly difference in HbA1c between COPD, DM2, COPD+DM2 and control subjects $(7.7 \pm 0.6$ vs $7.8 \pm 0.8 ; 7.9 \pm 0.9$ vs $4.0 \pm 0.2 \mathrm{mg} / \mathrm{dL}$; respectively, $(\mathrm{P}<0.005$ vs control; $\mathrm{P}:$ ns COPD vs DM2 vs COPD+DM2) (Fig. 2).

In particular, we reported that unbalance glycometabolic was more frequent in COPD woman vs COPD men $(23.5 \%$ vs $18.6 \%$, respectively; $\mathrm{P}<0.0001$ ).

\section{Discussion}

Glucose metabolism has not been studied extensively in COPD patients, and the available studies are inconclusive, perhaps due to differences in BMI and the hypoxemic state of this patient population $[14,15]$. Some studies have suggested that a reduced lung function could be a risk factor for the development of insulin resistance or diabetes [16, 17]. However, COPD patients with unbalance glycometabolic have more comorbidity and used more inhaled steroids [18]. There are a number of ways in which COPD might lead to the development of unbalance glycometabolic. Inflammatory markers that are increased in patients with type 2 diabetes have been observed to be up-regulated in patients with COPD [19]. The chronic state of inflammation in COPD patients is believed to shift the metabolism of the patients toward net protein catabolism, in turn increasing the resting energy expenditure [20]. As a result, the fat-free mass of such patients is depleted [21], which is accompanied by an increase in systemic markers of inflammation [22]. No differences were reported between gender [23]. Our preliminary study revealed that the prevalence of unbalance glycometabolic (as indicated by HbAlc $>7 \%$ ) in COPD patients was $>50 \%$ vs control. To this regard we reported that women with COPD seemed to be at high risk to develop unbalance glycometabolic (23.5\% women and $18.6 \%$ men) vs $1.5 \%$ women and $0.9 \%$ men in control population. These results are in agreeing con previous study by Cazzola et al [23]. The authors have been indicated that the prevalence of diabetes mellitus in woman COPD was 17.6\% [23].

The mechanisms by which COPD may increase a woman's risk of unbalance glycometabolic are not fully understood. We reported a high risk to develop unbalance glycometabolic in elderly women because this may be associated to different body weight, total body water and pharmacokinetic and pharmacodynamic profile. This would require the administration of cortisone in older women as a function of the parameters indicated. In particular, it would be desirable to provide for the administration of cortisone in this group of patients in relation to body weight, for example.

The other explanation is that these diseases may share a common inflammatory basis with type 2 diabetes. COPD is inflammatory lung disorders involving multiple inflammatory pathways [24]. Elevated circulating levels of the inflammatory cytokines have been associated with the development of prediabetic insulin resistance and the progression in unbalance glycometabolic [25]. Another potential limitation is that the higher risk of unbalance glycometabolic among individuals with COPD may have been mediated, at least in part, by the use of systemic corticosteroids [26]. In this regard, the risk of developing corticosteroid-induced diabetes has only been seen with the use of systemic steroids [27]. Recently the limit, to use these drugs, was recommended for FEV1 values $<$ below $60 \%$ of the predicted value [11]. A dose of 30 - $40 \mathrm{mg}$ prednisolone per day for 10 - 14 days is recommended [28]. There are insufficient data to provide firm conclusions concerning the optimal duration of corticosteroid therapy of acute exacerbations of COPD [29]. The patient with chronic obstructive pulmonary disease is in the 
majority of cases an elderly patient, overweight with BMI greater than $25 \mathrm{~kg} / \mathrm{m}^{2}$, who takes corticosteroids [30,31] and almost one-half of the patients with COPD had coexisting metabolic syndrome [32]. In fact, half of all patients hospitalized for COPD exacerbations have elevated random blood glucose $\geq 7 \mathrm{mmoL} / \mathrm{L}$ [33]. This hyperglycemia is caused not only by glucose intolerance below (5-18\% have a diagnosis of diabetes mellitus), or physiological stress of acute illness but is linked to use of steroids prior to hospital admission (18\% of patients) [34].

In our study, at least one-half of the patients with COPD, GOLD stage 2 and stage 3 had a coexisting unbalance glycometabolic. This frequency is in line with the findings of an epidemiologic study [35] from Germany using the criteria of International Diabetes Federation. In this epidemiologic study the prevalence of the metabolic syndrome in individuals between 60 and 65 years of age was $55 \%$ in men and $45 \%$ in women [35].

Men and women differ in response to drug treatment and occupational exposures, a consequence of differences in body weight, height, body surface area, total body water, and the amount of extracellular and intracellular water [36]. Women are generally smaller and have a different body composition than men, the recommended dose may result in higher drug concentrations or area under the concentration time curve (AUC) in women because the drug has lower clearance and/or smaller volume of distribution $\left(V_{d}\right)$ [37]. Alternatively, pharmacodynamic actors (alterations in drugtarget numbers or responses) may increase female sensitivity to specific drugs [38].

Routes of absorption occur across body surfaces, such as the gastrointestinal tract, respiratory tract, or skin, which differ in males and females. For example, drug absorption occurs at different sites throughout the gastrointestinal tract, and rate of absorption is influenced by gut transit times, lipid solubility of the agent, $\mathrm{pH}$ at the site of absorption, and the ionization and molecular weight of the agent [39]. Transit times differ significantly in men and women, with mean transit times being shorter in men ( 44.8 hours) than in women (91.7 hours) [40]. Sex differences have also been noted in bile acid composition, which may impact the solubility of various drugs [41].

Additionally, women have greater respiratory minute ventilation and lower tidal volume, which may result in decreased ingestion of inhaled aerosol drugs [41]. Body fat as a percentage of total body weight is higher in women than in men and increases by age in both sexes [42]. The larger proportions of body fat in women may increase the body burden of lipid soluble, slowly metabolized toxicants. Renal clearance is generally higher in men [43]. To this regard the guidelines on the management of COPD in women do not address this issue in detail, although the number of COPD women with unbalance glycometabolic is considerable and significant $[1,23]$.
A careful monitoring of blood glucose in hospitalized patients has been shown to significantly improve the intraand post-hospital mortality, with significant reduction in the average length of stay [12].

Everything should be carefully considered because a high rate of unplanned readmission rates may indicate a poor clinical management which will also increase the burden on the health care system in the long term.

In the long term, this may represent an important tool for the prevention of acute exacerbation of COPD in woman patients. Future evidence-based preventive strategies should be developed and implemented to improve the overall health burden in woman with COPD who are also at high risk for other chronic comorbidities.

\section{References}

1. Gold Global Initiative for Chronic Obstructive Lung Disease. Global Strategy for the Diagnosis, Management, and Prevention of Chronic Obstuctive Pulmonary Disease. Updated 2013.

2. Lung and Asthma Information Agency. Trends in COPD. Fact sheet 2003/1. Public Health Services Dept., St George's Hospital Medical School, Cranmer Terrance, London, UK.

3. Celli BR, Barnes PJ. Exacerbations of chronic obstructive pulmonary disease. Eur Respir J. 2007;29(6):12241238.

4. Connors AF, Jr., Dawson NV, Thomas C, Harrell FE, Jr., Desbiens N, Fulkerson WJ, Kussin P, et al. Outcomes following acute exacerbation of severe chronic obstructive lung disease. The SUPPORT investigators (Study to Understand Prognoses and Preferences for Outcomes and Risks of Treatments). Am J Respir Crit Care Med. 1996;154(4 Pt 1):959-967.

5. Seneff MG, Wagner DP, Wagner RP, Zimmerman JE, Knaus WA. Hospital and 1-year survival of patients admitted to intensive care units with acute exacerbation of chronic obstructive pulmonary disease. JAMA. 1995;274(23):1852-1857.

6. Wilkinson TM, Donaldson GC, Hurst JR, Seemungal TA, Wedzicha JA. Early therapy improves outcomes of exacerbations of chronic obstructive pulmonary disease. Am J Respir Crit Care Med. 2004;169(12):1298-1303.

7. Quon BS, Gan WQ, Sin DD. Contemporary management of acute exacerbations of COPD: a systematic review and metaanalysis. Chest. 2008;133(3):756-766.

8. Celli BR, MacNee W. Standards for the diagnosis and treatment of patients with COPD: a summary of the ATS/ ERS position paper. Eur Respir J. 2004;23(6):932-946.

9. ATS statement--Snowbird workshop on standardization of spirometry. Am Rev Respir Dis. 1979;119(5):831838. 
10. Sterk PJ. Let's not forget: the GOLD criteria for COPD are based on post-bronchodilator FEV1. Eur Respir J. 2004;23(4):497-498.

11. Calverley PM, Anderson JA, Celli B, Ferguson GT, Jenkins C, Jones PW, Yates JC, et al. Salmeterol and fluticasone propionate and survival in chronic obstructive pulmonary disease. N Engl J Med. 2007;356(8):775-789.

12. ADA - American Diabetes Association. Diabetes Care. 2013;36:20-26.

13. Hu FB, Manson JE, Stampfer MJ, Colditz G, Liu S, Solomon CG, Willett WC. Diet, lifestyle, and the risk of type 2 diabetes mellitus in women. N Engl J Med. 2001;345(11):790-797.

14. Chan JM, Rimm EB, Colditz GA, Stampfer MJ, Willett WC. Obesity, fat distribution, and weight gain as risk factors for clinical diabetes in men. Diabetes Care. 1994;17(9):961-969.

15. Hjalmarsen A, Aasebo U, Birkeland K, Sager G, Jorde R. Impaired glucose tolerance in patients with chronic hypoxic pulmonary disease. Diabetes Metab. 1996;22(1):37-42.

16. Lazarus R, Sparrow D, Weiss ST. Baseline ventilatory function predicts the development of higher levels of fasting insulin and fasting insulin resistance index: the Normative Aging Study. Eur Respir J. 1998;12(3):641645.

17. Engstrom G, Hedblad B, Nilsson P, Wollmer P, Berglund $\mathrm{G}$, Janzon L. Lung function, insulin resistance and incidence of cardiovascular disease: a longitudinal cohort study. J Intern Med. 2003;253(5):574-581.

18. Jesus Diez-Manglano, Jose Barquero-Romero, Pedro Almagro, Francisco Javier Cabrera, Francisco Lopez Garcia, Lorena Montero, Joan Baptiste Soriano. COPD patients with and without metabolic syndrome: clinical and functional differences. Internal and Emergency Medicine May. 2013.

19. Chung KF. Cytokines in chronic obstructive pulmonary disease. Eur Respir J Suppl. 2001;34:50s-59s.

20. Wouters EF. Chronic obstructive pulmonary disease. 5: systemic effects of COPD. Thorax. 2002;57(12):10671070.

21. Mador MJ. Muscle mass, not body weight, predicts outcome in patients with chronic obstructive pulmonary disease. Am J Respir Crit Care Med. 2002;166(6):787789.

22. Vermeeren MA, Schols AM, Wouters EF. Effects of an acute exacerbation on nutritional and metabolic profile of patients with COPD. Eur Respir J. 1997;10(10):22642269.

23. Cazzola M, Bettoncelli G, Sessa E, Cricelli C, Biscione G. Prevalence of comorbidities in patients with chronic obstructive pulmonary disease. Respiration. 2010;80(2):112-119.

24. Agusti AG, Noguera A, Sauleda J, Sala E, Pons J, Bus- quets X. Systemic effects of chronic obstructive pulmonary disease. Eur Respir J. 2003;21(2):347-360.

25. Pradhan AD, Manson JE, Rifai N, Buring JE, Ridker PM. C-reactive protein, interleukin 6 , and risk of developing type 2 diabetes mellitus. JAMA. 2001;286(3):327-334.

26. Delaunay F, Khan A, Cintra A, Davani B, Ling ZC, Andersson A, Ostenson CG, et al. Pancreatic beta cells are important targets for the diabetogenic effects of glucocorticoids. J Clin Invest. 1997;100(8):2094-2098.

27. Gurwitz JH, Bohn RL, Glynn RJ, Monane M, Mogun H, Avorn J. Glucocorticoids and the risk for initiation of hypoglycemic therapy. Arch Intern Med. 1994;154(1):97101.

28. Davies L, Angus RM, Calverley PM. Oral corticosteroids in patients admitted to hospital with exacerbations of chronic obstructive pulmonary disease: a prospective randomised controlled trial. Lancet. 1999;354(9177):456-460.

29. Alia I, de la Cal MA, Esteban A, Abella A, Ferrer R, Molina FJ, Torres A, et al. Efficacy of corticosteroid therapy in patients with an acute exacerbation of chronic obstructive pulmonary disease receiving ventilatory support. Arch Intern Med. 2011;171(21):1939-1946.

30. Spencer S, Calverley PM, Burge PS, Jones PW. Impact of preventing exacerbations on deterioration of health status in COPD. Eur Respir J. 2004;23(5):698-702.

31. Calverley PM, Spencer S, Willits L, Burge PS, Jones PW. Withdrawal from treatment as an outcome in the ISOLDE study of COPD. Chest. 2003;124(4):13501356.

32. Watz H, Waschki B, Kirsten A, Muller KC, Kretschmar G, Meyer T, Holz O, et al. The metabolic syndrome in patients with chronic bronchitis and COPD: frequency and associated consequences for systemic inflammation and physical inactivity. Chest. 2009;136(4):1039-1046.

33. Chakrabarti B, Angus RM, Agarwal S, Lane S, Calverley PM. Hyperglycaemia as a predictor of outcome during non-invasive ventilation in decompensated COPD. Thorax. 2009;64(10):857-862.

34. Louis M, Punjabi NM. Effects of acute intermittent hypoxia on glucose metabolism in awake healthy volunteers. J Appl Physiol (1985). 2009;106(5):1538-1544.

35. Moebus S, Hanisch JU, Aidelsburger P, Bramlage P, Wasem J, Jockel KH. Impact of 4 different definitions used for the assessment of the prevalence of the Metabolic Syndrome in primary healthcare: The German Metabolic and Cardiovascular Risk Project (GEMCAS). Cardiovasc Diabetol. 2007;6:22.

36. Soldin OP, Chung SH, Mattison DR. Sex differences in drug disposition. J Biomed Biotechnol. 2011;2011:187103.

37. Chen ML, Lee SC, Ng MJ, Schuirmann DJ, Lesko LJ, Williams RL. Pharmacokinetic analysis of bioequivalence trials: implications for sex-related issues in clinical 
pharmacology and biopharmaceutics. Clin Pharmacol Ther. 2000;68(5):510-521.

38. Coker SJ. Drugs for men and women - how important is gender as a risk factor for TdP? Pharmacol Ther. 2008;119(2):186-194.

39. Soldin OP, Mattison DR. Sex differences in pharmacokinetics and pharmacodynamics. Clin Pharmacokinet. 2009;48(3):143-157.

40. Stephen AM, Wiggins HS, Englyst HN, Cole TJ, Wayman BJ, Cummings JH. The effect of age, sex and level of intake of dietary fibre from wheat on large- bowel function in thirty healthy subjects. Br J Nutr. 1986;56(2):349-361.

41. Nicolas JM, Espie P, Molimard M. Gender and interindividual variability in pharmacokinetics. Drug Metab Rev. 2009;41(3):408-421.

42. Young CK, White S. Preparing patients for tube feeding at home. Am J Nurs. 1992;92(4):46-53.

43. Berg UB. Differences in decline in GFR with age between males and females. Reference data on clearances of inulin and PAH in potential kidney donors. Nephrol Dial Transplant. 2006;21(9):2577-2582. 